\title{
PCSK9 inhibitors in the prevention of cardiovascular disease
}

\author{
James Latimer $^{1} \cdot$ Jonathan A. Batty $^{1,3} \cdot$ R. Dermot G. Neely ${ }^{1,2} \cdot$ Vijay Kunadian $^{1,3}$
}

Published online: 19 April 2016

(c) The Author(s) 2016. This article is published with open access at Springerlink.com

\begin{abstract}
Reducing plasma levels of low-density lipoprotein cholesterol (LDL-C) remains the cornerstone in the primary and secondary prevention of cardiovascular disease. However, lack of efficacy and adverse effects mean that a substantial proportion of patients fail to achieve acceptable LDL-C levels with currently available lipid-lowering drugs. Over the last decade, inhibition of proprotein convertase subtilisin/kexin type 9 (PCSK9) has emerged as a promising therapeutic strategy to reduce residual cardiovascular disease risk. Binding of PCSK9 to the LDL receptor targets the receptor for lysosomal degradation. The recognition that inhibition of PCSK9 increases LDL receptor activity has led to the development of a number of approaches to directly target PCSK9. Numerous monoclonal antibodies against PCSK9 are currently being evaluated in phase 3 trials, involving various patient categories on different background lipid-lowering therapies. Current evidence shows reductions in LDL-C levels of up to $70 \%$ may be achieved with PCSK9 inhibition, independent of background statin therapy. This review examines the most recent evidence and future prospects for the use of PCSK9 inhibitors in the prevention of cardiovascular disease.
\end{abstract}

Vijay Kunadian

vijay.kunadian@newcastle.ac.uk

1 Institute of Cellular Medicine, Faculty of Medical Sciences, Newcastle University, M3.131, 3rd Floor William Leech Building, Newcastle upon Tyne NE2 4HH, UK

2 Royal Victoria Infirmary, Newcastle upon Tyne NHS Foundation Trust, Newcastle upon Tyne, UK

3 Freeman Hospital, Newcastle upon Tyne NHS Foundation Trust, Newcastle upon Tyne, UK
Keywords Low-density lipoprotein - Proprotein convertase subtilisin kexin type 9 (PCSK9) · Prevention . Monoclonal antibody $\cdot$ Evolocumab $\cdot$ Alirocumab

\section{Introduction}

Atherosclerotic cardiovascular disease (CVD) is the leading cause of mortality worldwide [1]. Atherosclerosis occurs as a consequence of metabolic and inflammatory changes to the arterial wall, which promote the macrophage-mediated intimal deposition of pro-atherogenic lowdensity lipoprotein cholesterol (LDL-C), contributing to plaque formation, limiting blood flow to vital organs and increasing the risk of atherothrombotic and atheroembolic sequelae. Dyslipidaemia has become an important risk factor to target in both the primary and secondary prevention of CVD. With the advent of statins, which inhibit 3-hydroxy-3-methylglutaryl-coenzyme A (HMG-CoA) reductase, sustained reductions in LDL-cholesterol have become achievable. Large-scale clinical trials demonstrate that a $40 \mathrm{mg} \mathrm{dL}^{-1}\left(1 \mathrm{mmol} \mathrm{L}^{-1}\right)$ decrease in LDL-C results in a $22 \%$ reduction in adverse cardiovascular events $[2,3]$. The overwhelming evidence of the clinical efficacy and cost-effectiveness of statins has led to their establishment as the first-line treatment of dyslipidaemia [4]. However, despite optimal statin therapy, less than half of recurrent cardiovascular events can be prevented. Indeed, satisfactory control of dyslipidaemia is not achieved in certain patients, even with combination lipidlowering therapy.

Impelled by the need for additional lipid management strategies, recent attention has focused on a new class of agent, proprotein convertase subtilisin/kexin type 9 (PSCK9) inhibitors. These demonstrate much promise, 
particularly for those unable to take statins, e.g. due to adverse effects or drug-drug interactions [5]. The discovery of PCSK9-based therapies began in 2003, with an astute clinical observation of a French family, which demonstrated features of familial hypercholesterolemia $(\mathrm{FH})$, without mutations in the genes contemporaneously recognised to cause $\mathrm{FH}$; the LDL receptor gene (LDLR, accounting for $95 \%$ of $\mathrm{FH}$ defects), or apolipoprotein B gene, encoding the protein that binds to the LDLR (ApoB, accounting for $4 \%$ of FH defects) [6, 7]. These findings led to the identification of two novel missense mutations that increased the activity of a serine protease enzyme, originally called neural apoptosis-regulated convertase 1 (NARC-1) and subsequently renamed proprotein convertase subtilisin/kexin type 9 [8]. This discovery has led to novel therapeutic options in lipid management $[9,10]$. The goals of this review are to explore the mechanism of action of PCSK9 inhibitors and their potential to improve cardiovascular outcomes.

\section{The structure and function of PCSK9}

\section{Synthesis and structure}

PCSK9, found at chromosome $1 \mathrm{p} 32$, is $22 \mathrm{~kb}$ in length, with 12 exons that encode a 692-amino acid protein [11]. It is a proteinase $\mathrm{K}$-like enzyme, belongs to the secretory subtilase family and is primarily synthesised and secreted by hepatocytes $[12,13]$. The synthesis of PCSK9 is upregulated by sterol-regulatory-element-binding protein-2 (SREBP-2), a transcription factor that regulates PCSK9 expression by binding to the sterol-regulatory element in the promoter region of the gene [14]. SREBP-2 also increases LDL receptor and cholesterol synthesis, via the activation of genes encoding key enzymes involved in cholesterol homeostasis, including HMG-CoA reductase [15]. It is activated by low intracellular cholesterol concentrations. SREBP-2 and PCSK9 expression is suppressed in fasting mice fed a cholesterol-rich diet [16]. Prolonged fasting in animals and humans, however, also causes a decrease in PCSK9 and SREBP-2 activity [17]. In addition, in vivo evidence suggests a possible role for insulin in increasing the expression of PCSK9 [18].

The PCSK protein product is comprised of a N-terminal signal peptide, prodomain, catalytic domain, hinge region, and cysteine-rich C-terminal domain [13, 19]. Following the removal of the signal peptide domain, PCSK9 is synthesised as a $\sim 74 \mathrm{kDa}$ zymogen, which undergoes autocatalytic cleavage in the endoplasmic reticulum and Golgi body, to generate a pro-domain fragment and $\sim 62 \mathrm{kDa}$ mature protein, which remain strongly associated to one another [20-22].

\section{LDL receptor cycling}

The first 8 members of the PCSK family, PCSK 1-8, are serine proteases involved in the processing of inactive precursor proteins to generate functional and bioactive peptides, polypeptides and hormones, which play important roles in regulating growth and metabolism [23-25]. In contrast, PCSK9 plays a crucial role in the regulation of LDL receptor recycling [26]. The PCSK9 complex binds to the epidermal growth factor A (EGF-A) domain of the LDL receptor, leading to the lysosomal degradation of the latter and reduced clearance of circulating LDL-C. Extrahepatic actions of PCSK9 include enhancement of chylomicron secretion and regulation of enterocyte cholesterol balance [13]. Moreover, data from experimental models suggest that the role of PCSK9 extends beyond lipid homeostasis; it is implicated as a regulator of glucose metabolism, liver regeneration and susceptibility to hepatitis $\mathrm{C}$ virus infection [27-30].

In mouse models, the accumulation of cholesteryl esters in aortic atherosclerotic lesions was markedly reduced by PCSK9 inactivation [31]. Conversely, overexpression of PCSK9 induced an excess burden of atherosclerosis. In LDLR-deficient mice, knockdown or overexpression of PCSK9 had no significant effects on cholesteryl ester accumulation or atheromatous plaque size. This study strongly suggested that the process by which PCSK9 enhances atherosclerosis is primarily mediated by its action on the LDLR [31]. Figure 1 displays normal, physiological LDLR recycling.

In humans studies, PCSK9 loss-of-function mutations have been associated with reductions in LDL-C and cardiovascular events [32]. Conversely, those with high levels of PCSK9 have higher level of plasma LDL-C and significantly increased lifetime CVD risk [32]. Gain-of-function mutations on PCSK9 are associated with a severe form of autosomal dominant hypercholesterolemia, phenotypically indistinguishable from $\mathrm{FH}$ due to LDL-receptor mutations [32].

\section{Regulation}

PCSK9 concentrations demonstrate a diurnal rhythm synchronous to cholesterol synthesis, with changes of $\pm 15 \%$ from the mean value [33]. PCSK9 synthesis also induced by insulin and repressed by glucagon in rodents [18]. In healthy humans, PCSK9 levels are demonstrably reduced with fasting (decreasing $60 \%$ over $36 \mathrm{~h}$ ), and increase in the post-prandial period, suggesting a similar effect [3335]. In addition, PCSK9 is positively controlled by the oxysterol-activated liver X receptor (LXR) $[18,36]$.

PCSK9 circulates in plasma in three main forms [37]. When secreted, PCSK9 exists as a monomer, but can self- 
Fig. 1 Normal, physiological LDLR recycling. $L D L$ low density lipoprotein, $L D L-C$ lowdensity lipoprotein cholesterol, $L D L R$ low density lipoprotein receptor

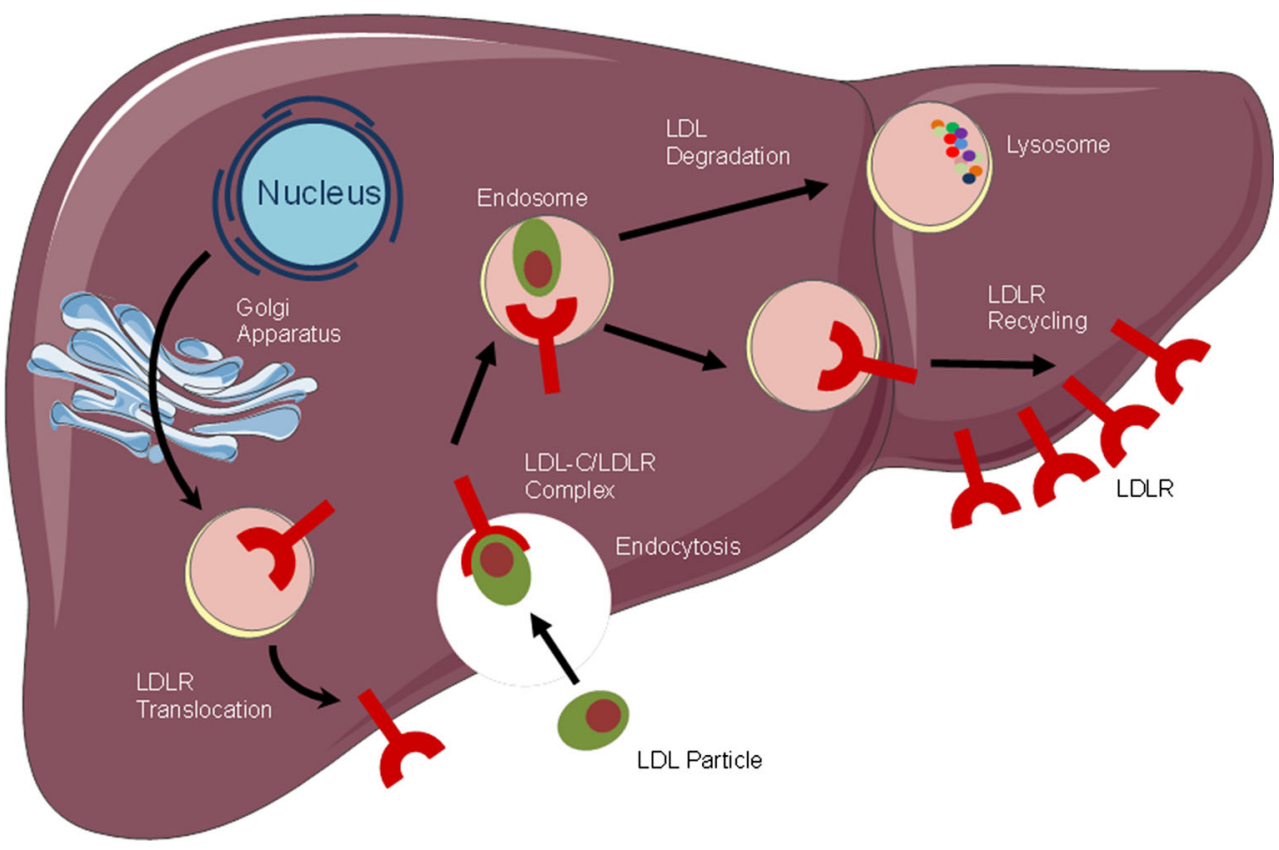

associate into di- and trimeric complexes, facilitated by the catalytic domain. It is present in free and protein-bound forms in human plasma, with $40 \%$ of circulating PCSK9 exclusively associated with LDL [16]. LDL-bound PCSK9 has diminished LDL receptor-binding activity. It has been proposed that this is a regulatory mechanism, by which higher plasma concentrations of LDL results in a greater proportion of LDL-bound PCSK9, thereby inhibiting PCSK9-mediated degradation of the LDL receptor [16]. In vitro evidence suggests that self-associated di-/trimers have enhanced LDL receptor-binding and degrading activity, compared with the monomer form [38]. PCSK9 also circulates as a $55 \mathrm{kDa}$ furin-cleaved inactive fragment, resulting from the cleavage of the $62 \mathrm{kDa}$ protein: mutations in the mature PCSK9 protein have been associated with increased or decreased susceptibility to furin cleavage, leading PCSK9 loss-of-function and gain-of-function phenotypes [22].

\section{Mechanism of action}

PCSK9 acts primarily as a soluble protein, targeting degradation of the membrane-bound LDLR by extracellular binding via rerouting to the lysosomal pathway [39]. At the molecular level, PCSK9 blocks the LDLR in an extended (open) conformation. This is achieved when the catalytic domain of PCSK9 (aa153-421) and the EGF-A domain of LDLR (aa314-355) bind [40]. This failure of the receptor to adopt a closed conformation results in a slowed recycling to the plasma membrane and subsequent degradation. LDL-receptors-like PCSK9-are particularly abundant in the liver, the primary organ responsible for clearance of plasma LDL. As the number of LDL-receptors on the surface of liver cells determines the rate of LDL removal from the bloodstream, PCSK9 presented an appealing target to beneficially modulate lipid homeostasis. Figure 2 illustrates the mechanism of action of PCSK9.

Impelled by promising pre-clinical evidence, the clinical development of therapeutic inhibitors of PCSK9 has progressed rapidly, with promising results reported from phase 2 and 3 clinical studies, in statin-intolerant and familial hypercholesterolemia patients, with sub-optimal LDL-C levels.

\section{PCSK9 inhibitors}

\section{Inhibition strategies}

Several strategies have been proposed for targeting PCSK9. Messenger RNA (mRNA) knockdown approaches, which include the use of PCSK9 antisense oligonucleotides, have been evaluated in animal models. Antisense oligonucleotides administered to mice reduced PCSK9 expression by $>90 \%$ and lowered plasma cholesterol levels by $53 \%[41,42]$. A single intravenous injection of PCSK9 RNA interference (RNAi) delivered in lipidoid nanoparticles to cynomolgus monkeys reduced plasma PCSK9 and LDL-C levels (by 70 and $56 \%$, respectively) [43]. However, the use of monoclonal antibodies (mAb), which interfere with the interaction of the PCSK9 catalytic domain and LDLR, is particularly promising [44]. In 
Fig. 2 Mechanism of action of PCSK9. $L D L$ low density lipoprotein, $L D L-C$ low-density lipoprotein cholesterol, $L D L R$ low density lipoprotein receptor, PCSK9 proprotein convertase subtilisin/kexin type 9

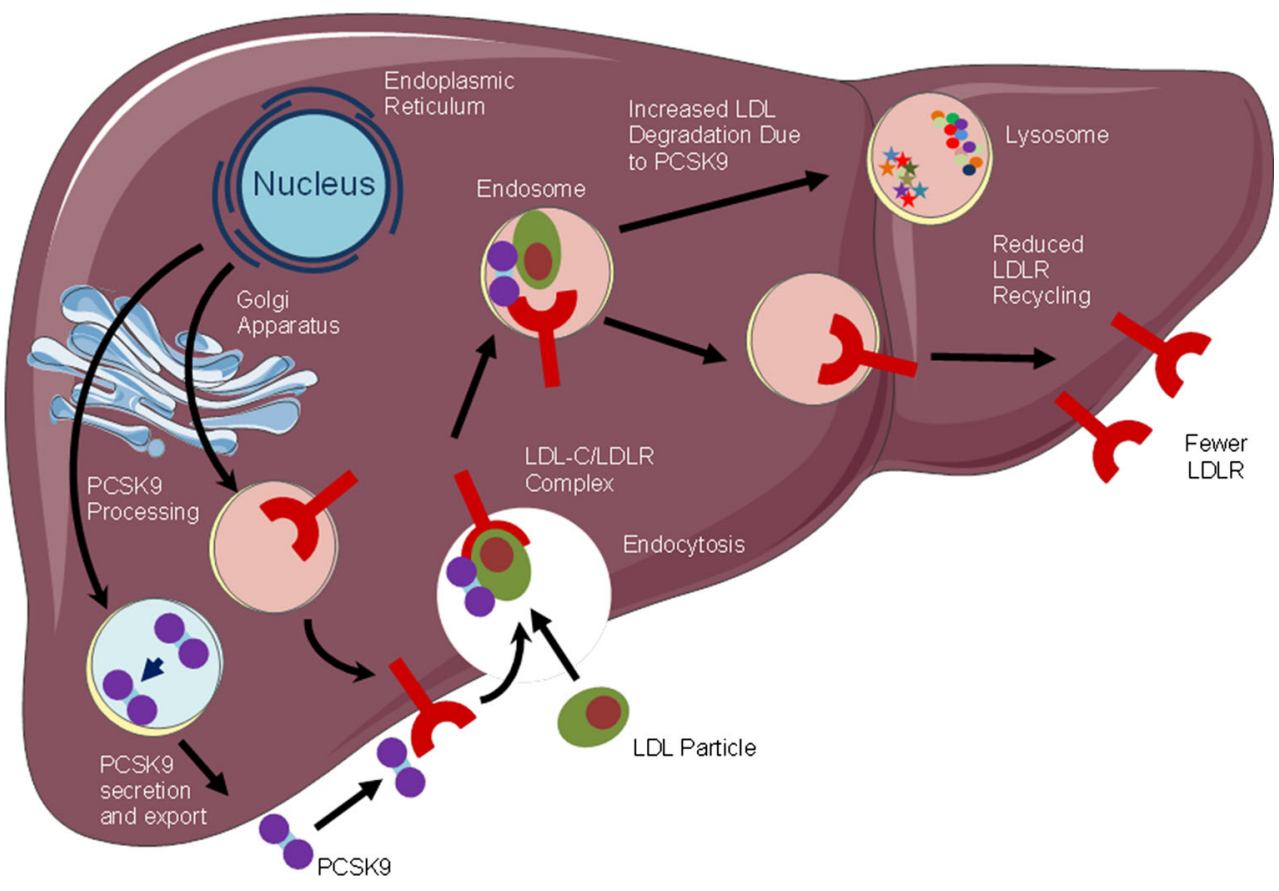

nonhuman primates, intravenous infusion of mAb1 $\left(3 \mathrm{mg} \mathrm{kg}^{-1}\right)$, which is specific for the catalytic domain of PCSK9, resulted in marked $(80 \%)$ reduction in plasma LDL-C [45].

PCSK inhibition may yield non-LDL-lowering, pleiotropic effects. High levels of lipoprotein(a) are an independent predictor of cardiovascular mortality, even in statin-treated patients with low LDL-C [46]. PCSK9 inhibitors reduce lipoprotein(a) by approximately $30 \%$. Such an effect is not observed with statin- or ezetimibemediated upregulation of LDL receptor activity (as lipoprotein(a) is not cleared by LDLR-dependent mechanisms, and is mainly regulated by hepatic secretion) [47]. Thus, PCSK9 inhibition as a therapeutic strategy has theoretical advantages beyond LDL-C lowering, raising the possibility that cardiovascular outcomes may be additionally favourable. Figure 3 displays the mechanism of action of PCSK9 $\mathrm{mAb}$, in the presence of a statin.

In clinical studies, three monoclonal antibodies have demonstrated significant promise: evolocumab (AMG145), alirocumab (SAR236553/REGN727) and bococizumab; the latter of which is in the early stages of development. Table 1 lists PCSK9 inhibitors in development.

\section{Evolocumab}

\section{Evolocumab in primary hypercholesterolemia}

Evolocumab is a fully human monoclonal antibody inhibitor of PCSK9. In the Monoclonal Antibody Against PCSK9 to Reduce Elevated LDL-C in Patients Currently
Not Receiving Drug Therapy for Easing Lipid Levels (MENDEL) trial, 406 patients with hypercholesterolaemia and statin intolerance were randomly assigned to evolocumab 70, 105 and $140 \mathrm{mg}$ every 2 weeks; evolocumab 280, 350 and $420 \mathrm{mg}$ every 4 weeks; placebo every 2 weeks or every 4 weeks, or ezetimibe once-daily. Evolocumab reduced LDL-C concentrations in all dose groups, with the maximal effect for the regimen of $140 \mathrm{mg}$ every 2 weeks $(\sim 51 \%)$ and no reported treatment-related adverse events [48].

MENDEL-2 evaluated the efficacy, safety and tolerability of evolocumab compared with placebo and oral ezetimibe in 614 patients with hypercholesterolemia (LDL-C $100-190 \mathrm{mg} \mathrm{dL}^{-1}$ or $2.6-4.9 \mathrm{mmol} \mathrm{L}^{-1}$ ) [49]. Patients 18-80 years of age with Framingham risk scores $\geq 10 \%$ were randomised to one of six groups; (i) oral placebo and sub-cutaneous (SC) placebo fortnightly; (ii) oral placebo and SC placebo monthly; (iii) ezetimibe and SC placebo fortnightly; (iv) ezetimibe and SC placebo monthly; (v) oral placebo and evolocumab $140 \mathrm{mg}$ fortnightly; or (vi) oral placebo and evolocumab $420 \mathrm{mg}$ monthly. Evolocumab treatment produced greatest reductions in LDL-C from baseline, by $55-57 \%$ more than placebo and 38-40\% more than ezetimibe (both $p<0.001$ ).

In the LDL-C Assessment With PCSK9 monoclonal Antibody Inhibition Combined With Statin therapy (LAPLACE TIMI-57), 631 patients with hypercholesterolemia on statins were randomised to different regimens of evolocumab, with varying dosages and intervals of administration: $70 \mathrm{mg}, 105 \mathrm{mg}$, and $140 \mathrm{mg}$ or matching 
Fig. 3 Mechanism of action of PCSK9 $\mathrm{mAb}$ in presence of a statin. $L D L$ low density lipoprotein, $L D L-C$ low-density lipoprotein cholesterol, $L D L R$ low density lipoprotein receptor, PCSK 9 proprotein convertase subtilisin/kexin type 9

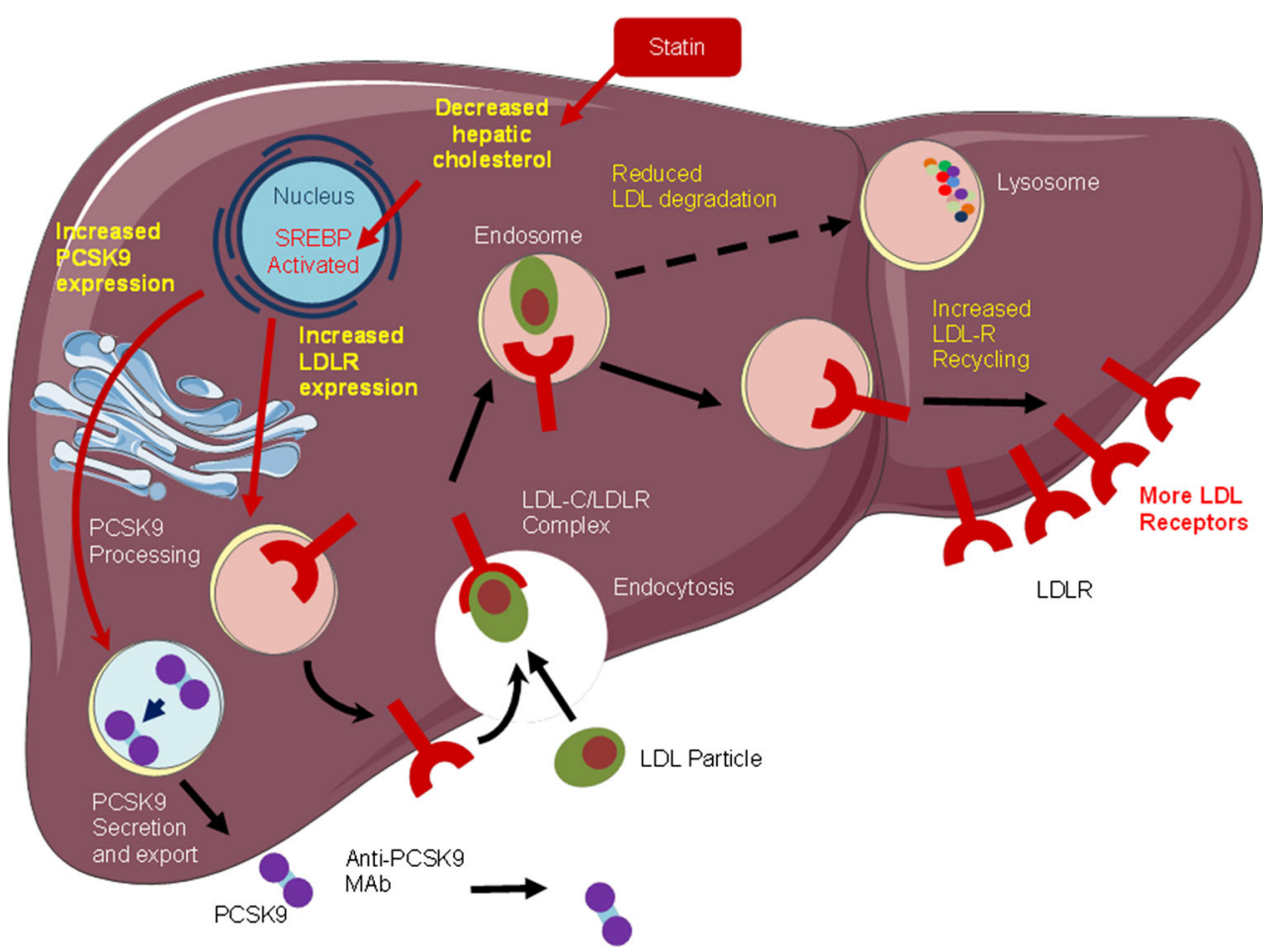

Table 1 I PCSK9 Inhibitors undergoing preclinical and clinical evaluation

\begin{tabular}{llll}
\hline Pharmaceutical company & Drug class & Agent & \\
\hline Sanofi/Regeneron & Human mAb & Alicocumab (SAR236553/REGN727) & 3 \\
Amgen & Human mAb & Evolocumab (AMG 145) & 3 \\
Pfizer/Rinat & mAb & Bococizumab (RN316) \\
Novartis & mAb & LGT-209 & 2 \\
Roche/Genetech & mAb & RG7652 & 2 \\
Alnylam Pharmaceuticals/The Medicines Company & siRNA oligonucleotide & ALN-PCS02 & 1 \\
Bristol-Myers Squibb/Adnexus & Monobody & BMS-962476 & 1 \\
Idera Pharmaceuticals & Antisense Oligonucleotide & TBD & PC \\
Merck & mAb & 1D05-IgG2 & PC \\
Schering-Plough & Mimetic peptides & LDL EGF-AB peptide fragment & PC \\
\hline
\end{tabular}

$m A b$ monoclonal antibody, $P C$ pre-clinical, siRNA small interfering ribonucleic acid

placebo every 2 weeks; or $280 \mathrm{mg}, 350 \mathrm{mg}$, and $420 \mathrm{mg}$ or matching placebo every 4 weeks [50]. At week 12, the mean LDL-C concentration reduction was dose-dependent, ranging from 41.8 to $66.1 \%$ every 2 weeks, and from 41.8 to $50.3 \%$ every 4 weeks [51]. The LAPLACE-2 trial assessed the response to addition of evolocumab (140 mg every 2 weeks or $420 \mathrm{mg}$ monthly) vs. placebo, to moderate- or high-intensity statin therapy in 1896 patients with hyperlipidaemia [52]. The trial observed that evolocumab reduced plasma LDL-C concentrations by $66-75 \%$, vs. placebo, at the mean of weeks 10 and 12. Evolocumab added to statin therapy resulted in additional LDL-C lowering.
More recently, the Durable Effect of PCSK9 Antibody CompARed wiTh placEbo Study (DESCARTES) placed patients into one of four background lipid-lowering strategies (dietary changes alone, dietary changes plus atorvastatin $10 \mathrm{mg}$, dietary changes plus atorvastatin $80 \mathrm{mg}$, and dietary changes plus atorvastatin $80 \mathrm{mg}$ and ezetimibe $10 \mathrm{mg}$ ) based on their LDL-C levels and cardiovascular risk [53]. Individuals with LDL-C $\geq 75 \mathrm{mg} / \mathrm{dl}$ were randomised to receive monthly $\mathrm{SC}$ evolocumab $420 \mathrm{mg}$ or placebo. The mean reduction in LDL-C from baseline in the evolocumab group was $57.0 \pm 2.1 \%$ $(\mathrm{p}<0.001$ vs. placebo). The mean reduction was $55.7 \pm 4.2 \%$ among patients who underwent dietary 
changes alone, $61.6 \pm 2.6 \%$ among those who received $10 \mathrm{mg}$ of atorvastatin, $56.8 \pm 5.3 \%$ among those who received $80 \mathrm{mg}$ of atorvastatin, and $48.5 \pm 5.2 \%$ among those who received a combination of $80 \mathrm{mg}$ of atorvastatin and $10 \mathrm{mg}$ of ezetimibe ( $p<0.001$ for all comparisons). Evolocumab treatment also significantly reduced levels of apolipoprotein B, lipoprotein(a) and triglycerides.

\section{Evolocumab in familial hypercholesterolemia}

In the Reduction of LDL-C with PCSK9 Inhibition in Heterozygous Familial Hypercholesterolemia Disorder (RUTHERFORD) trial, 167 patients with heterozygous FH $(\mathrm{HeFH})$ and poorly-controlled LDL-C $\left(\geq 2.6 \mathrm{mmol} \mathrm{L}^{-1}\right.$ or $100 \mathrm{mg} \mathrm{dL}^{-1}$ ) despite maximally-tolerated statin therapy, were randomised 1:1:1 to receive evolocumab $350 \mathrm{mg}$, $420 \mathrm{mg}$ or matched placebo, every four weeks. A substantial reduction in LDL-C was observed (43\% for $350 \mathrm{mg}$ vs. $55 \%$ for $420 \mathrm{mg}$ ) in addition to that due to high-intensity statin therapy [54]. RUTHERFORD-2 subsequently evaluated evolocumab in combination with other lipid-lowering therapies in patients with $\mathrm{HeFH}$ [55]. In total, $331 \mathrm{HeFH}$ patients unable to achieve target LDL-C (defined as per RUTHERFORD) despite maximally-tolerated statin alone, or in combination with ezetimibe, were randomised $2: 1$ to receive evolocumab $140 \mathrm{mg}$ every 2 weeks, evolocumab $420 \mathrm{mg}$ monthly, or matched placebo, for 12 weeks. Based on the Simon Broome criteria, $80 \%$ of participants had definite $\mathrm{FH} ; 20 \%$ had probable FH. All patients received a statin; two-thirds received ezetimibe. Both schedules demonstrated significant reduction in mean LDL-C at week $12(59.2 \%$ for $140 \mathrm{mg}$ every 2 weeks vs. $61.3 \%$ for $420 \mathrm{mg}$ monthly; both $\mathrm{p}<0.0001$ ).

Classically, homozygous $\mathrm{FH}(\mathrm{HoFH})$ patients were thought to have dual null mutations, conferring no LDL receptor activity, and thus would not be expected to respond to PCSK9 inhibition (which is LDL receptordependent). Indeed, a small proportion of FH patients are true genetic homozygotes, with identical null or loss-offunction mutations in both alleles of the affected gene. However, advanced genetic profiling has demonstrated that most patients with homozygous loss-of-function mutations are actually compound heterozygotes, with different receptor mutations. As such, HoFH patients may be phenotypically stratified using fibroblast culture; those with $<2 \%$ of LDL uptake are receptor negative; those with 2-25\% are receptor defective, compared to wild-type controls [56]. Thus, patients with HoFH may still have a degree of functional LDL receptor activity, which is associated with severity of LDL cholesterol elevation, and may be modulated via PCSK9 inhibition. Indeed, in the recent Trial Evaluating PCSK9 Antibody in Subjects With LDL Receptor Abnormalities (TESLA) Part B study, 50 patients with $\mathrm{HoFH}$, on stable lipid-lowering therapy and not on lipoprotein apheresis, received evolocumab $420 \mathrm{mg}$ monthly, in addition to statin therapy and other lipid-lowering medications [57]. Indeed, TESLA demonstrated that in the Evolocumab-treated HoFH patients, LDL-C was reduced by $31 \%$ from baseline at week 12 compared with placebo $(\mathrm{p}<0.0001)$; no serious adverse side effects were noted.

\section{Evolocumab in statin-intolerant patients}

With infrequent reports of adverse effects, PCSK9 inhibitors have been heralded as a potentially effective alternative treatment option for those who are statin-intolerant. Muscle-related side effects (MRSE) are the commonest reason given for discontinuation of statins. Worldwide, the incidence of myopathy is $1.5-5 \%$ of statin-treated patients, although this is highly-dependent on the definition used [58]. One study found that mild-to-moderate muscular symptoms occurred more frequently in patients treated with high-dose statins in clinical practice (in $10.5 \%$ ), compared to randomised trials [59]. However, another reported that most patients discontinuing statins due to MRSE that are re-challenged demonstrate good tolerance long-term [60]. Despite the uncertainties regarding the true incidence of MRSE, there is a clear clinical need for alternative therapies in patients at high cardiovascular risk, with more severe degrees of myotoxicity [58].

The Goal Achievement After Utilizing an Anti-PCSK9 Antibody in Statin Intolerant Subjects (GAUSS) study aimed to establish whether there was an advantage to evolocumab over ezetimibe in this context [61]. In the GAUSS trial, 160 patients with statin intolerance were randomised to 5 groups: evolocumab alone at 280, 350, $420 \mathrm{mg}$, evolocumab at $420 \mathrm{mg}$ with $10 \mathrm{mg}$ ezetimibe once-daily, or $10 \mathrm{mg}$ ezetimibe plus placebo once-daily. Statin intolerance was defined as the inability to tolerate at least one statin at any dose, or an increase in dose, because of intolerable myalgia (muscle pain, soreness, weakness, or cramps) or myopathy (myalgia plus elevated creatine kinase) and having symptom improvement or resolution with statin discontinuation. The administration of evolocumab was significantly associated with a reduction in LDL-C levels, ranging from 40 to $65 \%$, with good tolerability; myalgia was reported in: $7.4 \%$ receiving evolocumab alone, $20 \%$ receiving the evolocumab and ezetimibe combination, and $3.1 \%$ receiving ezetimibe and placebo [61]. GAUSS-2 assessed statin-intolerant hyperlipidaemic patients $[62,63]$. Intolerance was defined as inability to tolerate any dose, or increase the dose above the smallest tablet strength, because of intolerable musclerelated side effects. Evolocumab (140 mg every 2 weeks or $420 \mathrm{mg}$ monthly) reduced LDL-C from baseline by 53 and 
$56 \%$ respectively, when compared with ezetimibe (37-39\% reduction from baseline; $p<0.001)$. MRSE occurred in $12 \%$ of evolocumab-treated patients vs. $23 \%$ of ezetimibe-treated patients.

\section{Evolocumab and cardiovascular outcomes}

In the OSLER (Open Label Study of Long Term Evaluation Against LDL-C) trial, 4465 patients were randomised to receive either evolocumab $420 \mathrm{mg}$ monthly, or $140 \mathrm{mg}$ every two weeks, and followed up for a median of 11.1 months. The results demonstrated that evolocumab reduced the plasma concentration of LDL cholesterol by $61 \%$, from a median of $120 \mathrm{mg} \mathrm{dL}^{-1}\left(3.1 \mathrm{mmol} \mathrm{L}^{-1}\right)$ to $48 \mathrm{mg} \mathrm{dL}^{-1}\left(1.2 \mathrm{mmol} \mathrm{L}^{-1} ; p<0.001\right)$. The rate of a composite cardiovascular endpoint (defined as death, acute coronary syndrome, heart failure, stroke or a transient ischaemic attack) at 1 year was reduced from $2.18 \%$ in the standard-therapy group to $0.95 \%$ in the evolocumab group [Hazard Ratio (HR) 0.47; $95 \%$ confidence interval (95\% CI) $0.28-0.78 ; p=0.003)$. A large proportion of these patients were receiving statin therapy at baseline $(69.7 \%$ of evolocumab-treated patients vs. $70.9 \%$ of those receiving placebo), though no conclusions are drawn regarding the efficacy of evolocumab over and above statin therapy. Table 2 displays phase 2 studies evaluating evolocumab.

\section{Alirocumab}

\section{Effect of alirocumab in primary hypercholesterolemia}

Alirocumab is a fully human monoclonal antibody to PCSK9. Phase II trials demonstrated that as monotherapy, alirocumab can reduce LDL-C as much as intensive statin treatment [64]. The phase III, double-blind, double-dummy ODYSSEY-MONO trial evaluated the safety and efficacy of alirocumab as monotherapy in comparison with ezetimibe, over 24 weeks in patients with primary hypercholesterolemia and moderate cardiovascular risk, not otherwise receiving statins or other lipid-lowering therapy [65]. A total of 103 patients with LDL-C 2.6-4.9 mmol $\mathrm{L}^{-1}\left(100-190 \mathrm{mg} \mathrm{dL}^{-1}\right)$, and 1-5\% 10-year risk of fatal cardiovascular events (estimated via the Systematic COronary Risk Evaluation [SCORE] tool) were randomised to receive either ezetimibe $10 \mathrm{mg}$ or alirocumab, with the aim to achieve target HDL-C using the minimum effective dose of anti-PCSK9 antibody. Alirocumab was initially selfadministered at a dose of $75 \mathrm{mg}$ every 2 weeks, and uptitrated to $150 \mathrm{mg}$ if LDL-C at week 8 was $>1.8 \mathrm{mmol} \mathrm{L}^{-1}$ $\left(70 \mathrm{mg} \mathrm{dL}{ }^{-1}\right)$. Mean LDL-C reductions of $47 \%$ with alirocumab vs. $16 \%$ with ezetimibe were observed (intention-to-treat analysis; $p<0.0001 ; 54$ vs. $17 \%$, on- treatment analysis; $p<0.0001)$. Prior to up-titration, alirocumab $75 \mathrm{mg}$ every 2 weeks reduced LDL-C by $53 \%$, indicating low-dose alirocumab is sufficient to provide $50 \%$ LDL-C reduction in the majority of patients.

The ODYSSEY-COMBO trials evaluated the efficacy of alirocumab in addition to maximally-tolerated daily statin therapy vs. ezetimibe, in patients with hypercholesterolemia and additional CVD risk factors [66, 67]. In ODYSSEY-COMBO II, alirocumab lowered LDL-C levels significantly more than ezetimibe, at both week 24 (50.6 vs. $20.7 \%$ respectively; $p<0.0001)$ and $52(49.5$ vs. $18.3 \%$ respectively; $p<0.001)$. In addition, more alirocumab-treated than ezetimibe-treated patients achieved target LDL-C levels $\left(\leq 1.8 \mathrm{mmol} \mathrm{L}^{-1}, \leq 70 \mathrm{mg} \mathrm{dL}^{-1}\right)$ by week 24 (77 vs. $45.6 \% ; p<0.0001)$. The ODYSSEYOPTIONS studies demonstrated that the addition of alirocumab to statin regimens produced significantly greater LDL-C reductions than the addition of ezetimibe, doubling of statin dose, or switch to high-potency agent such as rosuvastatin $[68,69]$.

\section{Alirocumab in familial hypercholesterolemia}

The ODYSSEY programme (comprising ODYSSEY-FH I, II, HIGH FH and LONG-TERM trials) assessed the efficacy and safety of alirocumab in HeFH subjects with LDL$\mathrm{C}$ treatment targets dependent on cardiovascular risk status: $<2.6 \mathrm{mmol} \mathrm{L}^{-1}\left(<100 \mathrm{mg} \mathrm{dL}{ }^{-1}\right)$ in patients without documented CVD and $<1.8 \mathrm{mmol} \mathrm{L}^{-1}\left(<70 \mathrm{mg} \mathrm{dL}^{-1}\right)$ in patients with prior CVD [70-72]. Alirocumab administered at 75 or $150 \mathrm{mg}$ every 2 weeks reduced LDL-C by $48.8 \%$ in FH I and $48.7 \%$ in FH II, respectively, from baseline to week 24, compared with an increase in the placebo arms (9.1\% in FH I; $2.8 \%$ in FH II, respectively; $p<0.0001$ for all comparisons). By week 24, more alirocumab-treated patients reached LDL-C treatment goals vs. placebo-treated patients (72.2 vs. $2.4 \%$ in FH I, and 81.4 vs. $11.3 \%$ in FH II; both $\mathrm{p}<0.0001)$. The mean achieved LDL-C levels in alirocumab-treated patients were $1.92 \mathrm{mmol} \mathrm{L}^{-1}(74.3 \mathrm{mg}$ $\mathrm{dL}^{-1}$; FH I) and $1.70 \mathrm{mmol} \mathrm{L}^{-1}\left(65.9 \mathrm{mg} \mathrm{dL}^{-1}\right.$; FH II) at week 52. ODYSSEY LONG-TERM assessed the longterm safety and tolerability of alirocumab in 2341 patients with either: (i) $\mathrm{HeFH}$, with or without manifestations of CVD, or (ii) primary hypercholesterolemia and coronary artery disease, with LDL-C inadequately controlled despite maximally-tolerated lipid-modifying pharmacotherapy (44\% received a high-intensity statin at recruitment) [73]. At 24 weeks, mean LDL-C was reduced from baseline by $61 \%$ for alirocumab-treated patients, and increased by $0.8 \%$ for patients treated with placebo $(p<0.0001)$. LDL-C goals of $\geq 50 \%$ reduction from baseline were attained in alirocumab-treated patients vs. placebo $(76 \%$ vs. $2 \% p<0.0001$ for LDL-C $<2.6 \mathrm{mmol}$ 


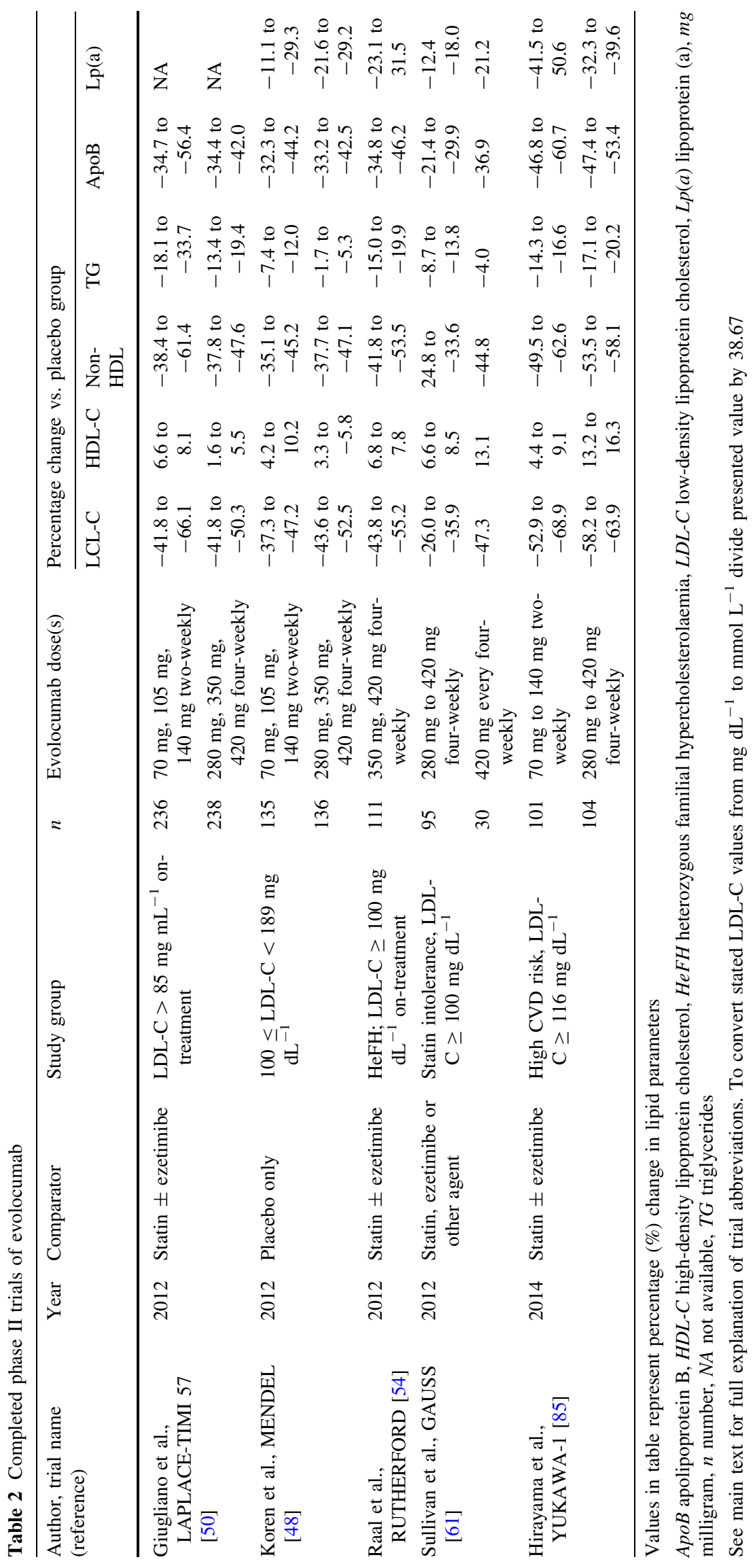


Table 3 Completed phase II trials of alirocumab

\begin{tabular}{|c|c|c|c|c|c|c|c|c|c|c|c|}
\hline \multirow{2}{*}{$\begin{array}{l}\text { Author } \\
\text { (reference) }\end{array}$} & \multirow[t]{2}{*}{ Year } & \multirow[t]{2}{*}{ Comparator } & \multirow[t]{2}{*}{ Study group } & \multirow[t]{2}{*}{$n$} & \multirow[t]{2}{*}{ Evolocumab dose(s) } & \multicolumn{6}{|c|}{ Percentage change vs. placebo group } \\
\hline & & & & & & LCL-C & $\begin{array}{l}\text { HDL- } \\
\mathrm{C}\end{array}$ & $\begin{array}{l}\text { Non- } \\
\text { HDL }\end{array}$ & TG & ApoB & $\mathrm{Lp}(\mathrm{a})$ \\
\hline \multirow[t]{2}{*}{$\begin{array}{l}\text { McKenney } \\
\text { et al. [78] }\end{array}$} & \multirow[t]{2}{*}{2012} & \multirow[t]{2}{*}{$\begin{array}{l}\text { Atorvastatin } \\
10,20 \\
\text { or } 40 \mathrm{mg}\end{array}$} & \multirow{2}{*}{$\begin{array}{l}\text { LCL- } \\
\mathrm{C} \geq 100 \mathrm{mg} \\
\mathrm{dL}^{-1} \text { on- } \\
\text { treatment }\end{array}$} & \multirow[t]{2}{*}{92} & $\begin{array}{l}50 \mathrm{mg}, 100 \mathrm{mg}, 150 \mathrm{mg} \\
\text { two-weekly }\end{array}$ & $\begin{array}{l}-34.5 \\
\text { to } \\
-67.3\end{array}$ & $\begin{array}{l}5.1 \text { to } \\
7.7\end{array}$ & $\begin{array}{l}-31.4 \\
\text { to } \\
-60.3\end{array}$ & $\begin{array}{l}-15.2 \\
\text { to } \\
-28.6\end{array}$ & $\begin{array}{l}-29.5 \\
\text { to } \\
-58.3\end{array}$ & $\begin{array}{l}-13.3 \\
\text { to } \\
-28.6\end{array}$ \\
\hline & & & & & $\begin{array}{l}200 \mathrm{mg}, 300 \mathrm{mg} \text { four- } \\
\text { weekly }\end{array}$ & $\begin{array}{l}-38.1 \\
\text { to } \\
-42.6\end{array}$ & $\begin{array}{l}7.3 \text { to } \\
9.5\end{array}$ & $\begin{array}{l}-35.2 \\
\text { to } \\
-38.5\end{array}$ & $\begin{array}{l}-18.1 \\
\text { to } \\
-20.5\end{array}$ & $\begin{array}{l}-30.9 \\
\text { to } \\
-35.3\end{array}$ & $\begin{array}{r}-7.9 \text { to } \\
-16.7\end{array}$ \\
\hline \multirow{2}{*}{$\begin{array}{l}\text { Roth et al. } \\
\text { [77] }\end{array}$} & \multirow[t]{2}{*}{2012} & \multirow{2}{*}{$\begin{array}{l}\text { Atorvastatin } \\
10 \text { or } \\
80 \mathrm{mg}\end{array}$} & \multirow{2}{*}{$\begin{array}{l}\text { LCL- } \\
\mathrm{C} \geq 100 \mathrm{mg} \\
\mathrm{dL}^{-1} \text { on- } \\
\text { treatment }\end{array}$} & \multirow[t]{2}{*}{60} & $150 \mathrm{mg}$ two-weekly & -48.9 & 6.2 & -36.0 & 7.9 & -42.4 & -32.0 \\
\hline & & & & & $150 \mathrm{mg}$ four-weekly & -55.9 & 9.4 & -41.6 & -12.8 & -46.0 & -28.2 \\
\hline \multirow[t]{2}{*}{$\begin{array}{l}\text { Stein et al. } \\
{[64]}\end{array}$} & \multirow[t]{2}{*}{2012} & \multirow[t]{2}{*}{$\begin{array}{l}\text { Statin } \pm \\
\quad \text { ezetimibe }\end{array}$} & \multirow{2}{*}{$\begin{array}{l}\mathrm{HeFH} ; \mathrm{LCL}- \\
\mathrm{C} \geq 100 \mathrm{mg} \\
\mathrm{dL}^{-1} \text { on- } \\
\text { treatment }\end{array}$} & 31 & $150 \mathrm{mg}$ two-weekly & $\begin{array}{l}-18.2 \\
\text { to } \\
-31.9\end{array}$ & $\begin{array}{l}4.3 \text { to } \\
7.8\end{array}$ & $\begin{array}{l}-15.5 \\
\text { to } \\
-27.6\end{array}$ & $\begin{array}{l}-6.2 \text { to } \\
5.6\end{array}$ & $\begin{array}{l}-14.5 \\
\text { to } \\
-22.0\end{array}$ & $\begin{array}{l}-3.54 \\
\text { to } \\
-11.4\end{array}$ \\
\hline & & & & & $\begin{array}{l}150 \mathrm{mg}, 200 \mathrm{mg}, \\
300 \mathrm{mg} \text { four-weekly }\end{array}$ & -57.3 & 10.1 & -46.6 & -5.7 & -43.8 & -19.47 \\
\hline
\end{tabular}

Values in table represent percentage (\%) change in lipid parameters

$A p o B$ apolipoprotein B, $H D L-C$ high-density lipoprotein cholesterol, $H e F H$ heterozygous familial hypercholesterolaemia, $L D L-C$ low-density lipoprotein cholesterol, $\operatorname{Lp}(a)$ lipoprotein (a), $m g$ milligram, $n$ number, $N A$ not available, $T G$ triglycerides. See main text for full explanation of trial abbreviations

To convert stated LDL-C values from $\mathrm{mg} \mathrm{dL}^{-1}$ to $\mathrm{mmol} \mathrm{L}^{-1}$ divide presented value by 38.67

$\mathrm{L}^{-1}$ or $<100 \mathrm{mg} \mathrm{dL}^{-1}$ and 81 vs. $9 \% ; p<0.0001$ for LDL-C $<1.8 \mathrm{mmol} \mathrm{L}^{-1}$ or $<70 \mathrm{mg} \mathrm{dL}^{-1}$ ). Most recently, these results have been reported to be maintained up to 78 weeks of treatment, with good tolerance [74]. Table 3 displays phase 2 studies evaluating alirocumab.

\section{The safety of PCSK9 inhibition}

So far, the clinical experience with monoclonal antibodies directed toward PCSK9 suggests that they are safe and well-tolerated, with no major safety issues and no evidence of serious drug-related adverse events [75]. The most common adverse events were nasopharyngitis, upper respiratory tract infections, influenza-like symptoms and back pain; injection site reactions were infrequent $(<2$ and $<4 \%$ of alirocumab and ezetimibe-treated patients, respectively) [76]. Isolated reports of adverse effects include: generalised pruritus after the first dose of alirocumab [64], delayed hypersensitivity-type reaction with rash, 12 days following the second injection of alirocumab [77], and a case of cutaneous leucocytoclastic vasculitis reported 9 days after initiation of alirocumab [78]. All of these patients responded well to withdrawal of the trial drug. Regarding completed phase III trials, in GAUSS-2, MRSE occurred in $12 \%$ of evolocumab-treated, and $23 \%$ of ezetimibe-treated patients [62]; in LAPLACE-2, adverse events were reported in 36,40 , and $39 \%$ of evolocumab-, ezetimibe- and placebo-treated patients, respectively [52].
None of the evolocumab-treated patients developed serious adverse reactions. However, elevations in creatine kinase (CK) of 3-10 times the upper limit of normal have been reported in a total of 12 study drug-treated, and 4 placebotreated patients. No deaths due to serious adverse events have been reported in PCSK9 clinical trials to date. Table 4 displays selected phase 3 studies of anti-PCSK 9 mAbs.

One putative concern regarding this new class of cholesterol-lowering drugs is the potential for hypocholesterolaemia-associated adverse effects, such as cognitive impairment. Indeed, even allowing for the technical difficulties of accurate LDL-C measurement at severely low levels, many subjects in phase 2 trials reached very low concentrations of LDL-C. Among those treated with alirocumab (150 mg every 2 weeks, for 12 weeks) in addition to atorvastatin, mean LDL-C was only $0.88 \pm 0.41 \mathrm{mmol} \mathrm{L}^{-1}\left(34 \pm 16 \mathrm{mg} \mathrm{dL}^{-1}\right)$ [78]. Preliminary analyses have not shown any evidence of a treatmentrelated increase in cognitive impairment [79]. Some studies have suggested an increased risk of haemorrhagic stroke at lower cholesterol concentrations [80]. The identification of rare patients with double loss of function (LOF) mutations in the PCSK9 gene provides some reassurance, however. Such individuals, who have very low plasma PCSK9 and LDL-cholesterol concentrations, appear healthy and without cardiovascular or neurocognitive impairment [81]. In addition, plasma LDL-C does not relate directly to the intracellular cholesterol concentrations involved in 


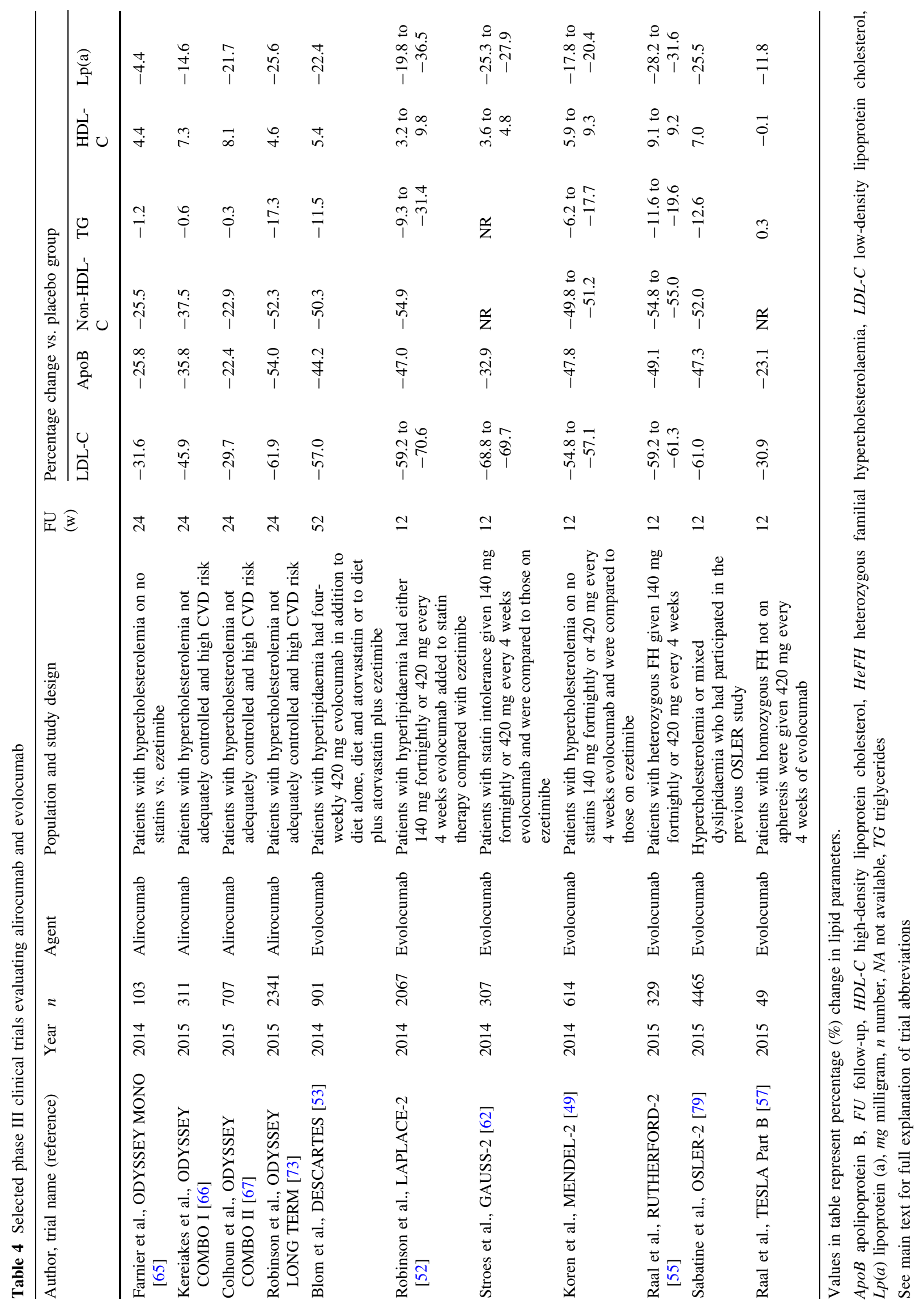


physiological functions (e.g. synthesis of hormones and vitamins) and thus, such concerns may be misplaced.

\section{Future directions}

Impelled by the growing evidence-base regarding the safety and efficacy of monoclonal PCSK9 inhibitors, considerable momentum has accumulated in the translation of this novel pharmacotherapeutic paradigm to clinical practice. However, there is still a need to evaluate whether PCSK9 inhibition yields benefits on cardiovascular endpoints, for patients with primary hypercholesterolemia. Indeed, three large phase III programmes with anti-PCSK9 monoclonal antibodies are currently ongoing to offer definitive insights into their utilisation in preventing cardiovascular events and improving clinical outcome: the PROFICIO and FOURIER programmes evaluating evolocumab, and the ODYSSEY programme evaluating alirocumab. A list of currently ongoing clinical studies is presented in Table 5. These trials are due to report in 2017-2018, and will surely offer greater insights into the safety and efficacy of PCSK9 inhibition, particularly with regard to effects over and above statin therapy.

In July 2015, the United States Food and Drug Administration (FDA) approved alirocumab as a second- line treatment, for adults with $\mathrm{HeFH}$, and those with proven CVD with hypercholesterolemia refractory to diet modification and maximally-tolerated statin therapy. One month later, the FDA similarly approved evolocumab for clinical usage. These approvals were conditional on the subsequent completion of planned phase III trials to determine efficacy in primary hypercholesterolemia. Both agents have also recently received marketing authorisation by the European Medicines Agency.

\section{Pharmacogenetic considerations}

Although the PCSK9 locus is polymorphic, evidence has not yet emerged to suggest that routine genetic testing would predict responsiveness to PCSK9 inhibition, in patients with primary hypercholesterolaemia. In patients with $\mathrm{HoFH}$, there exists evidence of differential response to PCSK9 inhibition, dependent on the specific underlying causative gene mutation(s). Evolocumab was demonstrably effective in lowering LDL-C, only in patients with residual LDL receptor function (the receptor-defective phenotype; 2-25\% function), but not receptor negative patients [54, 55, 57]. Stratification of FH patients, via fibroblast culture or pharmacogenetic testing (which many candidates may have underwent as part of FH diagnosis), may allow

Table 5 Major ongoing clinical studies of PCSK9 inhibitors

\begin{tabular}{|c|c|c|}
\hline Title & Description & $\begin{array}{l}\text { Study } \\
\text { identifier }\end{array}$ \\
\hline $\begin{array}{l}\text { Trial assessing efficacy, safety and tolerability of PCSK9 } \\
\text { inhibition in paediatric subjects with genetic LDL disorders }\end{array}$ & $\begin{array}{l}10-17 \text { year olds with outcomes focused on cardiovascular } \\
\text { risk }\end{array}$ & NCT02392559 \\
\hline $\begin{array}{l}\text { Effects of selective inhibition of cholesterol absorption with } \\
\text { ezetimibe on intestinal cholesterol homeostasis in dyslipidemic } \\
\text { men with insulin-resistance-a pilot study }\end{array}$ & Aged $18-60$ and has metabolic syndrome & NCT01849068 \\
\hline $\begin{array}{l}\text { Evaluating PCSK9 binding antibody influence on cognitive health } \\
\text { in high cardiovascular risk subjects }\end{array}$ & $\begin{array}{l}\text { Testing spatial working memory in those aged } 40 \text { to } 85 \\
\text { taking evolocumab }\end{array}$ & NCT02207634 \\
\hline $\begin{array}{l}\text { Further cardiovascular outcomes research with PCSK9 inhibition } \\
\text { in subjects with elevated risk }\end{array}$ & $\begin{array}{l}5 \text { year cardiovascular death, myocardial infarction, } \\
\text { hospitalization for unstable angina, stroke, or coronary } \\
\text { revascularization }\end{array}$ & NCT01764633 \\
\hline $\begin{array}{l}\text { The evaluation of bococizumab (PF-04950615; RN316) in } \\
\text { reducing the occurrence of major cardiovascular events in high } \\
\text { risk subjects }\end{array}$ & $\begin{array}{l}\text { Effect of bococizumab on number of Cardiovascular } \\
\text { Events }\end{array}$ & NCT01975389 \\
\hline $\begin{array}{l}\text { A phase } 1 \text { study of an investigational drug, ALN-PCSSC, in } \\
\text { subjects with elevated low density lipoprotein cholesterol (LDL- } \\
\text { C) }\end{array}$ & Safety & NCT02314442 \\
\hline $\begin{array}{l}\text { A 2-part, phase } 1 \text {, single and multiple ascending dose study to } \\
\text { assess the safety, pharmacokinetics, and pharmacodynamics of } \\
\text { CAT-2054 in healthy subjects }\end{array}$ & Frequency and severity of adverse events & NCT02374047 \\
\hline Open label study of long term evaluation against LDL-C trial-2 & Incidence of adverse events & NCT01854918 \\
\hline $\begin{array}{l}\text { ODYSSEY outcomes: evaluation of cardiovascular outcomes after } \\
\text { an acute coronary syndrome during treatment with alirocumab } \\
\text { SAR236553 (REGN727) }\end{array}$ & $\begin{array}{l}\text { To evaluate the effect of alirocumab on any adverse } \\
\text { cardiovascular event }\end{array}$ & NCT01663402 \\
\hline
\end{tabular}


personalised prediction of responsiveness to PCSK9 inhibition.

\section{Pharmacoeconomic considerations}

Since the approval of these agents by regulatory bodies, the uptake of PCSK9 inhibitors in US clinical practice has in large, been slow. This may be explained by several key factors. Priced over $\$ 14,000$ per year before discounts (\$14,100 for evolocumab, $\$ 14,600$ for alirocumab), and with a paucity of definitive data regarding improvements in cardiovascular outcomes, insurers have been reluctant to fund the available PCSK9 inhibitors. Recent pharmacoeconomic analysis by the US Institute for Clinical and Economic Review, calculated the overall price, best representing the potential benefits to patients, would be between \$3615 and 4811-a $67 \%$ discount on the current list price [82]. However, when compared to apheresis (the current best-available, alternative treatment, following statin and second-line medical therapy for uncontrolled hypercholesterolaemia), which costs approximately $\$ 8000$ per month $(\$ 96,000$ per year), the price of evolocumab and alirocumab appear more attractive. Schulman et al. estimate that in a typical insurance pool, if $5 \%$ of the estimated $27 \%$ of US adults 40-64 years of age who have hypercholesterolaemia were eligible for a PCSK9 inhibitor, annual premiums would increase by approximately $\$ 124$ per person; taxpayers would face the burden of similar increases in the cost of the Medicare Part D program [83].

\section{Conclusions}

A quarter century after approval of the first statin in 1987, reduction of LDL-C remains the best-validated treatment strategy in preventing cardiovascular disease. PCSK9 is a promising molecular target to reduce levels of LDL-C and other atherogenic lipoproteins, below levels achievable with statins. However, uncertainties remain regarding the long-term impact of therapeutic reduction of plasma LDL$\mathrm{C}$ to very low concentrations $\left(<1 \mathrm{mmol} \mathrm{L}^{-1}\right)$. Additionally, the increased risk of progression to diabetes seen with high-intensity statin treatment might also occur with PCSK9 inhibition, possibly resulting from the intracellular accumulation of lipids in insulin-secreting pancreatic beta cells [84]. However, more data are needed from large trials to exclude important emergent adverse effects of PCSK9 inhibitors. Although self-administered injections might not appear attractive for lifelong treatment, this route of administration may be acceptable to high-risk patients, unable to tolerate statins, or who need to achieve more stringent LDL-C targets. There seems little doubt that the advent of therapeutic PCSK9 inhibition heralds a change to the future of lipid management.

\section{Compliance with ethical standards}

Conflict of interest None.

Open Access This article is distributed under the terms of the Creative Commons Attribution 4.0 International License (http://creative commons.org/licenses/by/4.0/), which permits unrestricted use, distribution, and reproduction in any medium, provided you give appropriate credit to the original author(s) and the source, provide a link to the Creative Commons license, and indicate if changes were made.

\section{References}

1. Mendis S, Puska P, Norrving B (2011) Global atlas on cardiovascular disease prevention and control. World Health Organization, Geneva

2. Cholesterol Treatment Trialists C, Baigent C, Blackwell L, Emberson J, Holland LE, Reith C et al (2010) Efficacy and safety of more intensive lowering of LDL cholesterol: a meta-analysis of data from 170,000 participants in 26 randomised trials. Lancet 376(9753):1670-1681

3. Cholesterol Treatment Trialists C, Mihaylova B, Emberson J, Blackwell L, Keech A, Simes J et al (2012) The effects of lowering LDL cholesterol with statin therapy in people at low risk of vascular disease: meta-analysis of individual data from 27 randomised trials. Lancet 380(9841):581-590

4. Koo BK (2014) Statin for the primary prevention of cardiovascular disease in patients with diabetes mellitus. Diabetes Metab J 38(1):32-34

5. Corrao G, Conti V, Merlino L, Catapano AL, Mancia G (2010) Results of a retrospective database analysis of adherence to statin therapy and risk of nonfatal ischemic heart disease in daily clinical practice in Italy. Clin Ther 32(2):300-310

6. Abifadel M, Varret M, Rabès J-P, Allard D, Ouguerram K, Devillers $M$ et al (2003) Mutations in PCSK9 cause autosomal dominant hypercholesterolemia. Nat Genet 34(2):154-156

7. Graham CA, McIlhatton BP, Kirk CW, Beattie ED, Lyttle K, Hart P et al (2005) Genetic screening protocol for familial hypercholesterolemia which includes splicing defects gives an improved mutation detection rate. Atherosclerosis 182(2):331-340

8. Seidah NG, Benjannet S, Wickham L, Marcinkiewicz J, Jasmin SB, Stifani $S$ et al (2003) The secretory proprotein convertase neural apoptosis-regulated convertase 1 (NARC-1): liver regeneration and neuronal differentiation. Proc Natl Acad Sci 100(3):928-933

9. Lambert G, Sjouke B, Choque B, Kastelein JJP, Hovingh GK (2012) The PCSK9 decade thematic review series: new lipid and lipoprotein targets for the treatment of cardiometabolic diseases. J Lipid Res 53(12):2515-2524

10. Vogel RA (2012) PCSK9 inhibition: the next statin? J Am Coll Cardiol 59(25):2354-2355

11. Artenstein AW, Opal SM (2011) Proprotein convertases in health and disease. N Engl J Med 365(26):2507-2518

12. Maxwell KN, Breslow JL (2004) Adenoviral-mediated expression of Pcsk9 in mice results in a low-density lipoprotein receptor knockout phenotype. Proc Natl Acad Sci USA 101(18):7100-7105

13. Seidah NG, Prat A (2012) The biology and therapeutic targeting of the proprotein convertases. Nat Rev Drug Discovery 11(5): 367-383

14. Jeong HJ, Lee H-S, Kim K-S, Kim Y-K, Yoon D, Park SW (2008) Sterol-dependent regulation of proprotein convertase 
subtilisin/kexin type 9 expression by sterol-regulatory element binding protein-2. J Lipid Res 49(2):399-409

15. Goldstein JL, Brown MS (2009) History of discovery: the LDL receptor. Arterioscler Thromb Vasc Biol 29(4):431-438

16. Kosenko T, Golder M, Leblond G, Weng W, Lagace TA (2013) Low density lipoprotein binds to proprotein convertase subtilisin/ kexin type-9 (PCSK9) in human plasma and inhibits PCSK9mediated low density lipoprotein receptor degradation. J Biol Chem 288(12):8279-8288

17. Browning JD, Horton JD (2010) Fasting reduces plasma proprotein convertase, subtilisin/kexin type 9 and cholesterol biosynthesis in humans. J Lipid Res 51(11):3359-3363

18. Costet P, Cariou B, Lambert G, Lalanne F, Lardeux B, Jarnoux A-L et al (2006) Hepatic PCSK9 expression is regulated by nutritional status via insulin and sterol regulatory element-binding protein 1c. J Biol Chem 281(10):6211-6218

19. Benjannet S, Rhainds D, Essalmani R, Mayne J, Wickham L, Jin W et al (2004) NARC-1/PCSK9 and its natural mutants zymogen cleavage and effects on the low density lipoprotein (LDL) receptor and LDL cholesterol. J Biol Chem 279(47):48865-48875

20. Park SW, Moon Y-A, Horton JD (2004) Post-transcriptional regulation of low density lipoprotein receptor protein by proprotein convertase subtilisin/kexin type $9 \mathrm{a}$ in mouse liver. J Biol Chem 279(48):50630-50638

21. Nassoury N, Blasiole DA, Tebon Oler A, Benjannet S, Hamelin J, Poupon V et al (2007) The cellular trafficking of the secretory proprotein convertase PCSK9 and its dependence on the LDLR. Traffic 8(6):718-732

22. Lambert $G$ (2007) Unravelling the functional significance of PCSK9. Current opinion in lipidology 18(3):304-309

23. Turpeinen H, Ortutay Z, Pesu M (2013) Genetics of the first seven proprotein convertase enzymes in health and disease. Current genomics 14(7):453

24. Desai NR, Kohli P, Giugliano RP, O’Donoghue ML, Somaratne R, Zhou J et al (2013) AMG145, a monoclonal antibody against proprotein convertase subtilisin kexin type 9, significantly reduces lipoprotein(a) in hypercholesterolemic patients receiving statin therapy: an analysis from the LDL-C Assessment with Proprotein Convertase Subtilisin Kexin Type 9 Monoclonal Antibody Inhibition Combined with Statin Therapy (LAPLACE)-Thrombolysis in Myocardial Infarction (TIMI) 57 trial. Circulation 128(9):962-969

25. Couture F, D'Anjou F, Day R (2011) On the cutting edge of proprotein convertase pharmacology: from molecular concepts to clinical applications. Biomol Concepts 2(5):421-438

26. Cariou B, Le May C, Costet P (2011) Clinical aspects of PCSK9. Atherosclerosis 216(2):258-265

27. Levy E, Ouadda ABD, Spahis S, Sane AT, Garofalo C, Grenier É et al (2013) PCSK9 plays a significant role in cholesterol homeostasis and lipid transport in intestinal epithelial cells. Atherosclerosis 227(2):297-306

28. Farnier M (2014) PCSK9: from discovery to therapeutic applications. Archives of cardiovascular diseases 107(1):58-66

29. Farnier M (2013) PCSK9 inhibitors. Curr Opin Lipidol 24(3): 251-258

30. Bridge SH, Sheridan DA, Felmlee DJ, Crossey MM, Fenwick FI, Lanyon CV et al (2015) PCSK9, apolipoprotein E and lipoviral particles in chronic hepatitis $\mathrm{C}$ genotype 3: evidence for genotype-specific regulation of lipoprotein metabolism. J Hepatol 62(4):763-770

31. Denis M, Marcinkiewicz J, Zaid A, Gauthier D, Poirier S, Lazure C et al (2012) Gene inactivation of proprotein convertase subtilisin/kexin type 9 reduces atherosclerosis in mice. Circulation 125(7):894-901

32. Cohen JC, Boerwinkle E, Mosley TH Jr, Hobbs HH (2006) Sequence variations in PCSK9, low LDL, and protection against coronary heart disease. N Engl J Med 354(12):1264-1272
33. Persson L, Cao G, Ståhle L, Sjöberg BG, Troutt JS, Konrad RJ et al (2010) Circulating proprotein convertase subtilisin kexin type 9 has a diurnal rhythm synchronous with cholesterol synthesis and is reduced by fasting in humans. Arterioscler Thromb Vasc Biol 30(12):2666-2672

34. Browning JD, Horton JD (2010) Fasting reduces plasma proprotein convertase, subtilisin/kexin type 9 and cholesterol biosynthesis in humans. J Lipid Res 51(11):3359-3363

35. Persson L, Cao G, Stahle L, Sjoberg BG, Troutt JS, Konrad RJ et al (2010) Circulating proprotein convertase subtilisin kexin type 9 has a diurnal rhythm synchronous with cholesterol synthesis and is reduced by fasting in humans. Arterioscler Thromb Vasc Biol 30(12):2666-2672

36. Maxwell KN, Soccio RE, Duncan EM, Sehayek E, Breslow JL (2003) Novel putative SREBP and LXR target genes identified by microarray analysis in liver of cholesterol-fed mice. J Lipid Res 44(11):2109-2119

37. Tavori H, Giunzioni I, Linton MF, Fazio S (2013) Loss of plasma proprotein convertase subtilisin/kexin 9 (PCSK9) after lipoprotein apheresis. Circ Res 113(12):1290-1295

38. Fan D, Yancey PG, Qiu S, Ding L, Weeber EJ, Linton MF et al (2008) Self-association of human PCSK9 correlates with its LDLR-degrading activity. Biochemistry 47(6):1631-1639

39. Horton JD, Cohen JC, Hobbs HH (2007) Molecular biology of PCSK9: its role in LDL metabolism. Trends Biochem Sci 32(2):71-77

40. Leren TP (2014) Sorting an LDL receptor with bound PCSK9 to intracellular degradation. Atherosclerosis 237(1):76-81

41. Graham MJ, Lemonidis KM, Whipple CP, Subramaniam A, Monia BP, Crooke ST et al (2007) Antisense inhibition of proprotein convertase subtilisin/kexin type 9 reduces serum LDL in hyperlipidemic mice. J Lipid Res 48(4):763-767

42. Lindholm MW, Elmen J, Fisker N, Hansen HF, Persson R, Moller MR et al (2012) PCSK9 LNA antisense oligonucleotides induce sustained reduction of LDL cholesterol in nonhuman primates. Mol Ther 20(2):376-381

43. Frank-Kamenetsky M, Grefhorst A, Anderson NN, Racie TS, Bramlage B, Akinc A et al (2008) Therapeutic RNAi targeting PCSK9 acutely lowers plasma cholesterol in rodents and LDL cholesterol in nonhuman primates. Proc Natl Acad Sci USA 105(33): 11915-11920

44. Duff CJ, Scott MJ, Kirby IT, Hutchinson SE, Martin SL, Hooper NM (2009) Antibody-mediated disruption of the interaction between PCSK9 and the low-density lipoprotein receptor. Biochem J 419(3):577-584

45. Chan JC, Piper DE, Cao Q, Liu D, King C, Wang W et al (2009) A proprotein convertase subtilisin/kexin type 9 neutralizing antibody reduces serum cholesterol in mice and nonhuman primates. Proc Natl Acad Sci USA 106(24):9820-9825

46. Khera AV, Everett BM, Caulfield MP, Hantash FM, Wohlgemuth J, Ridker PM et al (2014) Lipoprotein(a) concentrations, rosuvastatin therapy, and residual vascular risk: an analysis from the JUPITER trial (justification for the use of statins in prevention: an intervention trial evaluating rosuvastatin). Circulation 129(6): 635-642

47. Rader DJ, Cain W, Ikewaki K, Talley G, Zech LA, Usher D et al (1994) The inverse association of plasma lipoprotein(a) concentrations with apolipoprotein(a) isoform size is not due to differences in $\mathrm{Lp}$ (a) catabolism but to differences in production rate. J Clin Invest 93(6):2758-2763

48. Koren MJ, Scott R, Kim JB, Knusel B, Liu T, Lei L et al (2012) Efficacy, safety, and tolerability of a monoclonal antibody to proprotein convertase subtilisin/kexin type 9 as monotherapy in patients with hypercholesterolaemia (MENDEL): a randomised, doubleblind, placebo-controlled, phase 2 study. Lancet 380(9858): 1995-2006 
49. Koren MJ, Lundqvist P, Bolognese M, Neutel JM, Monsalvo ML, Yang J et al (2014) Anti-PCSK9 monotherapy for hypercholesterolemia: the MENDEL-2 randomized, controlled phase III clinical trial of evolocumab. J Am Coll Cardiol 63(23): 2531-2540

50. Giugliano RP, Desai NR, Kohli P, Rogers WJ, Somaratne R, Huang F et al (2012) Efficacy, safety, and tolerability of a monoclonal antibody to proprotein convertase subtilisin/kexin type 9 in combination with a statin in patients with hypercholesterolaemia (LAPLACE-TIMI 57): a randomised, placebo-controlled, doseranging, phase 2 study. Lancet 380(9858):2007-2017

51. Giugliano RP, Desai NR, Kohli P, Rogers WJ, Somaratne R, Huang F et al (2012) Efficacy, safety, and tolerability of a monoclonal antibody to proprotein convertase subtilisin/kexin type 9 in combination with a statin in patients with hypercholesterolaemia (LAPLACE-TIMI 57): a randomised, placebo-controlled, doseranging, phase 2 study. Lancet 380(9858):2007-2017

52. Robinson JG, Nedergaard BS, Rogers WJ, Fialkow J, Neutel JM, Ramstad D et al (2014) Effect of evolocumab or ezetimibe added to moderate- or high-intensity statin therapy on LDL-C lowering in patients with hypercholesterolemia: the LAPLACE-2 randomized clinical trial. JAMA 311(18):1870-1882

53. Blom DJ, Hala T, Bolognese M, Lillestol MJ, Toth PD, Burgess L et al (2014) A 52-week placebo-controlled trial of evolocumab in hyperlipidemia. The New England journal of medicine 370(19): 1809-1819

54. Raal F, Scott R, Somaratne R, Bridges I, Li G, Wasserman SM et al (2012) Low-density lipoprotein cholesterol-lowering effects of AMG 145 , a monoclonal antibody to proprotein convertase subtilisin/kexin type 9 serine protease in patients with heterozygous familial hypercholesterolemia: the reduction of LDL-C with PCSK9 inhibition in heterozygous familial hypercholesterolemia disorder (RUTHERFORD) randomized trial. Circulation 126(20):2408-2417

55. Raal FJ, Stein EA, Dufour R, Turner T, Civeira F, Burgess L et al (2015) PCSK9 inhibition with evolocumab (AMG 145) in heterozygous familial hypercholesterolaemia (RUTHERFORD2): a randomised, double-blind, placebo-controlled trial. Lancet 385(9965):331-340

56. Hobbs HH, Brown MS, Goldstein JL (1992) Molecular genetics of the LDL receptor gene in familial hypercholesterolemia. Hum Mutat 1(6):445-466

57. Raal FJ, Honarpour N, Blom DJ, Hovingh GK, Xu F, Scott R et al (2015) Inhibition of PCSK9 with evolocumab in homozygous familial hypercholesterolaemia (TESLA Part B): a randomised, double-blind, placebo-controlled trial. Lancet 385(9965):341-350

58. Alfirevic A, Neely D, Armitage J, Chinoy H, Cooper RG, Laaksonen R et al (2014) Phenotype standardization for statininduced myotoxicity. Clin Pharmacol Ther 96(4):470-476

59. Bruckert E, Hayem G, Dejager S, Yau C, Bégaud B (2005) Mild to moderate muscular symptoms with high-dosage statin therapy in hyperlipidemic patients - the PRIMO study. Cardiovasc Drugs Ther 19(6):403-414

60. Zhang H, Plutzky J, Skentzos S, Morrison F, Mar P, Shubina M et al (2013) Discontinuation of statins in routine care settings: a cohort study. Ann Intern Med 158(7):526-534

61. Sullivan D, Olsson AG, Scott R, Kim JB, Xue A, Gebski V et al (2012) Effect of a monoclonal antibody to PCSK9 on low-density lipoprotein cholesterol levels in statin-intolerant patients: the GAUSS randomized trial. JAMA 308(23):2497-2506

62. Stroes E, Colquhoun D, Sullivan D, Civeira F, Rosenson RS, Watts GF et al (2014) Anti-PCSK9 antibody effectively lowers cholesterol in patients with statin intolerance: the GAUSS-2 randomized, placebo-controlled phase 3 clinical trial of evolocumab. J Am Coll Cardiol 63(23):2541-2548

63. Cho L, Rocco M, Colquhoun D, Sullivan D, Rosenson RS, Dent $R$ et al (2014) Design and rationale of the GAUSS-2 study trial: a double-blind, ezetimibe-controlled phase 3 study of the efficacy and tolerability of evolocumab (AMG 145) in subjects with hypercholesterolemia who are intolerant of statin therapy. Clin Cardiol 37(3):131-139

64. Stein EA, Gipe D, Bergeron J, Gaudet D, Weiss R, Dufour R et al (2012) Effect of a monoclonal antibody to PCSK9, REGN727/ SAR236553, to reduce low-density lipoprotein cholesterol in patients with heterozygous familial hypercholesterolaemia on stable statin dose with or without ezetimibe therapy: a phase 2 randomised controlled trial. Lancet 380(9836):29-36

65. Farnier M, Kastelein JJP, Roth E, Taskinen MR, Ginsberg HN, Colhoun HM et al (2014) Relationship between alirocumab, PCSK9 and LDL-C levels: results from the odyssey mono phase 3 trial of alirocumab $75 \mathrm{mg}$ every 2 weeks. Atherosclerosis 235(2): e34-e35

66. Kereiakes DJ, Robinson JG, Cannon CP, Lorenzato C, Pordy R, Chaudhari U, et al. (2015) Efficacy and safety of the PCSK9 inhibitor alirocumab among high cardiovascular risk patients on maximally tolerated statin therapy: the ODYSSEY COMBO I study. Am Heart J

67. Colhoun HM, Robinson JG, Farnier M, Cariou B, Blom D, Kereiakes DJ et al (2014) Efficacy and safety of alirocumab, a fully human PCSK9 monoclonal antibody, in high cardiovascular risk patients with poorly controlled hypercholesterolemia on maximally tolerated doses of statins: rationale and design of the ODYSSEY COMBO I and II trials. BMC Cardiovasc Disord 14(1):121

68. Schwartz GG, Bessac L, Berdan LG, Bhatt DL, Bittner V, Diaz R et al (2014) Effect of alirocumab, a monoclonal antibody to PCSK9, on long-term cardiovascular outcomes following acute coronary syndromes: rationale and design of the ODYSSEY outcomes trial. Am Heart J 168(5):682-689

69. Bays H, Gaudet D, Weiss R, Ruiz JL, Watts GF, Gouni-Berthold I et al (2015) Alirocumab as add-on to atorvastatin versus other lipid treatment strategies: ODYSSEY OPTIONS I randomized trial. J Clin Endocrinol Metabol 100(8):3140-3148

70. Kastelein JJP, Robinson JG, Farnier M, Krempf M, Langslet G, Lorenzato C et al (2014) Efficacy and safety of alirocumab in patients with heterozygous familial hypercholesterolemia not adequately controlled with current lipid-lowering therapy: design and rationale of the ODYSSEY FH studies. Cardiovasc Drugs Ther 28(3):281-289

71. Roth EM, Diller P (2014) Alirocumab for hyperlipidemia: physiology of PCSK9 inhibition, pharmacodynamics and Phase I and II clinical trial results of a PCSK9 monoclonal antibody. Future Cardiol 10(2):183-199

72. Ginsberg HN, Rader D, Raal FJ, Guyton J, Lorenzato C, Pordy R et al (2014) ODYSSEY high FH: efficacy and safety of alirocumab in patients with severe heterozygous familial hypercholesterolemia. Circulation 130(23):2119

73. Robinson JG, Farnier M, Krempf M, Bergeron J, Luc G, Averna $M$ et al (2015) Efficacy and safety of alirocumab in reducing lipids and cardiovascular events. N Engl J Med 372(16): 1489-1499

74. Kastelein JJP, Ginsberg HN, Langslet G, Hovingh GK, Ceska R, Dufour R et al (2015) ODYSSEY FH I and FH II: 78 week results with alirocumab treatment in 735 patients with heterozygous familial hypercholesterolaemia. Eur Heart J 36(43):2996-3003

75. Cicero AF, Tartagni E, Ertek S (2014) Safety and tolerability of injectable lipid-lowering drugs: a review of available clinical data. Exp Opin Drug Saf 13(8):1023-1030

76. Roth EM, Taskinen MR, Ginsberg HN, Kastelein JJ, Colhoun HM, Robinson JG et al (2014) Monotherapy with the PCSK9 inhibitor alirocumab versus ezetimibe in patients with hypercholesterolemia: results of a 24 week, double-blind, randomized Phase 3 trial. Int J Cardiol 176(1):55-61 
77. Roth EM, McKenney JM, Hanotin C, Asset G, Stein EA (2012) Atorvastatin with or without an antibody to PCSK9 in primary hypercholesterolemia. N Engl J Med 367(20):1891-1900

78. McKenney JM, Koren MJ, Kereiakes DJ, Hanotin C, Ferrand AC, Stein EA (2012) Safety and efficacy of a monoclonal antibody to proprotein convertase subtilisin/kexin type 9 serine protease, SAR236553/REGN727, in patients with primary hypercholesterolemia receiving ongoing stable atorvastatin therapy. J Am Coll Cardiol 59(25):2344-2353

79. Sabatine MS, Giugliano RP, Wiviott SD, Raal FJ, Blom DJ, Robinson J et al (2015) Efficacy and safety of evolocumab in reducing lipids and cardiovascular events. $\mathrm{N}$ Engl J Med 372(16):1500-1509

80. Prospective Studies C (2007) Blood cholesterol and vascular mortality by age, sex, and blood pressure: a meta-analysis of individual data from 61 prospective studies with 55000 vascular deaths. Lancet 370(9602):1829-1839

81. Zhao Z, Tuakli-Wosornu Y, Lagace TA, Kinch L, Grishin NV, Horton JD et al (2006) Molecular characterization of loss-of- function mutations in PCSK9 and identification of a compound heterozygote. Am J Hum Genet 79(3):514-523

82. The Institute for Clinical and Economic Review (ICER) (2015) PCSK9 inhibitor therapies for high cholesterol: effectiveness, value, and value-based price benchmarks (draft). The Institute for Clinical and Economic Review (ICER), Boston

83. Schulman KA, Balu S, Reed SD (2015) Specialty pharmaceuticals for hyperlipidemia-impact on insurance premiums. N Engl J Med 373(17):1591-1593

84. Preiss D, Seshasai SR, Welsh P, Murphy SA, Ho JE, Waters DD et al (2011) Risk of incident diabetes with intensive-dose compared with moderate-dose statin therapy: a meta-analysis. JAMA 305(24):2556-2564

85. Hirayama A, Honarpour N, Yoshida M, Yamashita S, Huang F, Wasserman SM et al (2014) Effects of evolocumab (AMG 145), a monoclonal antibody to PCSK9, in hypercholesterolemic, statintreated Japanese patients at high cardiovascular risk-primary results from the phase 2 YUKAWA study. Circ J 78(5):1073-1082 